\title{
A Study to Assess the Effect of Planned Teaching Program on Knowledge Regarding Interpretation of Cardiac Arrhythmias and its Management among Staff Nurses in Selected Hospitals of Pune City
}

Jerry Jacob*, Ranjana Tryambake, Vinita Jamdade and Veena Sakhardande

Department of Nursing, Bharati Vidyapeeth College of Nursing, Pune, India

*Corresponding author: Jerry Jacob, M. Sc Nursing student, Department of Nursing, Bharati Vidyapeeth College of Nursing, Pune, India, Tel: 8329580188; E-mail: jacob.jerry7@gmail.com

Received date: July 24, 2018; Accepted date: October 22, 2018; Published date: October 29, 2018

Copyright: (C) $2018 \mathrm{Jacob} \mathrm{J}$, et al. This is an open-access article distributed under the terms of the Creative Commons Attribution License, which permits unrestricted use, distribution, and reproduction in any medium, provided the original author and source are credited.

\begin{abstract}
Introduction: Any change in electrical conduction or automaticity of the heart causes disturbances in heart rate and rhythm, often referred to as cardiac arrhythmias.

Objectives: To assess the knowledge regarding interpretation of cardiac arrhythmias and it's management among staff nurses before and after planned teaching program, to compare the pre-test and post-test knowledge scores regarding interpretation of cardiac arrhythmias and it's management among staff nurses and to associate the pre-test score with selected demographic data.
\end{abstract}

Materials and methods: A quantitative research approach using pre-experimental pre-test post-test design was adopted for the study. Sister Callista Roy's adaptation model was adopted in the study, Non-Probability Convenient Sampling technique with 100 samples were selected from selected hospitals of Pune city. A self-structured questionnaire was used to collect the data during September 2017 to October 2017 to obtain the knowledge level.

Results: Findings of the study shows that majority of participants were females $(65 \%)$, working in critical care units (63\%) with Revised Diploma in General Nursing and Midwifery (78\%) in the age group of $20-25$ years (52\%) having attained no in-service education regarding cardiac arrhythmias $(77 \%)$. There was no association between knowledge scores and selected demographic variables. Pre-test knowledge scores; in the present study $64 \%$ of the samples had average knowledge regarding interpretation of cardiac arrhythmia's and its management Post-test knowledge scores increased after planned teaching program. $88 \%$ of samples had good knowledge regarding interpretation of cardiac arrhythmia's and its management.

Conclusion: A majority of nursing staff in ICU's can be helpful in prevention of critical condition and promotion of health. Thus, arises the need to train nurse's through educational programs which will benefit in early detection and diagnosis of cardiac arrhythmia's, reducing the mortality rate and improving quality of care provided.

Keywords: Knowledge; Cardiac arrhythmias; Staff nurses

\section{Introduction}

16 million deaths were reported globally due to cardiovascular disorders. Cardiac arrhythmias are some of the conditions which carry life threatening risks leading to heart failure or death, where early actions can play a great role in bringing back a patient from the clutches of death. Ventricular fibrillation is the most common dysrhythmia associated with sudden cardiac death, accounting for $65 \%$ to $80 \%$ of cardiac arrests [1-3].

\section{Materials and Methods}

A quantitative research approach using pre-experimental pre-test post-test design was adopted for the study. Sister Callista Roy's adaptation model was adopted in the study, non-probability convenient sampling technique with 100 samples were selected from selected hospitals of Pune city. A self-structured questionnaire was used to collect the data during September 2017 to October 2017 to obtain the knowledge level. The data were collected using selfstructured knowledge questionnaire which includes- Section- I: Demographic variables, Section-II: Structured questionnaire consisting of 25 multiple choice questions assessing knowledge regarding interpretation of cardiac arrhythmia's and its management. The scored are given as: 0-8 Poor, 9-16 Average and 17-25 as Good. Ethical approval was obtained from the ethical committee member. Written consent was taken from the participants.

\section{Results}

The analysis and interpretation of the data was done to determine the efficacy of the planned teaching program on knowledge regarding interpretation and management of cardiac arrhythmia's among staff nurses working in selected hospitals of Pune city. 52\% of samples were from the age group of $20-25,65 \%$ of samples were female, $78 \%$ of samples had degree of RGNM, $63 \%$ of samples had work experience in critical care units, $50 \%$ of samples had undergone in-service education. $64 \%$ of samples had average knowledge regarding interpretation of cardiac arrhythmias and its management before planned teaching 
Citation: Jacob J, Tryambake R, Jamdade V, Sakhardande V (2018) A Study to Assess the Effect of Planned Teaching Program on Knowledge Regarding Interpretation of Cardiac Arrhythmias and its Management among Staff Nurses in Selected Hospitals of Pune City. J Nurs Care 7: 463. doi:10.4172/2167-1168.1000463

Page 2 of 2

which improved after planned teaching as $88 \%$ of samples depicted good knowledge regarding interpretation of cardiac arrhythmias and it's management. This was supported by inferential statistics by using paired $\mathrm{t}$ test showed that there was marked increase in mean knowledge score after planned teaching program as calculated value of ' $\mathrm{t}$ ' was greater than tabulated value of ' $\mathrm{t}$ ' paired $\mathrm{t}$-test was significant; ' $\mathrm{t}$ ' $(99)=24.901$, at 0.05 level of significance. There was no association found between demographic variables with pre-test scores. There is no significant association between knowledge regarding interpretation of cardiac arrhythmias and it's management among staff nurses and selected demographic variables at 0.05 level of significance" (Tables 1 and 2).

\begin{tabular}{|l|l|l|l|l|}
\hline \multirow{2}{*}{$\begin{array}{l}\text { Knowledge } \\
\text { Score }\end{array}$} & \multicolumn{2}{|l|}{ Pre-test } & \multicolumn{2}{l|}{ Post-test } \\
\cline { 2 - 5 } & $\begin{array}{l}\text { Frequency } \\
\text { (f) }\end{array}$ & Percentage $\%$ & $\begin{array}{l}\text { Frequency } \\
\text { (f) }\end{array}$ & Percentage \% \\
\hline Poor (0-8) & 24 & $24 \%$ & 0 & $0 \%$ \\
\hline Average (09-16) & 64 & $64 \%$ & 12 & $12 \%$ \\
\hline Good (17-25) & 12 & $12 \%$ & 88 & $88 \%$ \\
\hline Total & 100 & 100 & 100 & 100 \\
\hline
\end{tabular}

Table 1: The findings related to knowledge of staff nurses regarding Interpretation of cardiac arrhythmias and it's management before and after planned teaching program $(n=100)$.

\begin{tabular}{|l|l|l|l|l|}
\hline Test & Mean & $\begin{array}{l}\text { Standard } \\
\text { deviation }\end{array}$ & $\begin{array}{l}\text { Calculated “t” } \\
\text { value }\end{array}$ & $\begin{array}{l}\text { Tabulated "t" } \\
\text { value }\end{array}$ \\
\hline Pre-test & 10.66 & 2.808 & $24.901^{* *}$ & 1.645 \\
\hline Post-test & 20.28 & 2.021 & -- & -- \\
\hline
\end{tabular}

Table 2: Findings related to efficacy of planned teaching in terms of difference between pre-test and post-test mean score $(n=100)$.

\section{Discussion}

Pre-test knowledge scores; in the current study samples had average knowledge regarding interpretation of cardiac arrhythmia's and its management. Samples had good knowledge regarding interpretation and management of cardiac arrhythmias after planned teaching program. There was no association between knowledge scores with selected demographic variables.

\section{Conclusion}

The conclusion drawn from the findings of the study is that there is positive influence of educational programs in early detection and management of cardiac arrhythmia's among staff nurses, reducing the mortality rate and improving quality of care provided.

\section{Recommendations}

The following recommendations were made for future research:

- Study could be replicated in other intensive care units and wards of selected institute.

- Study could be replicated by increasing the size of the sample.

- Similar study would be replicated to asses the difference in knowledge score's of staff who have attended in-service education/ training programme and those who did not attend any in-service education/training programme.

\section{Acknowledgement}

We express our appreciations to the respected officials of the Bharati Vidyapeeth Deemed University, College of Nursing, Pune for cooperating with us for executing this research. My sincere thanks to all the Participants of the study who made this study possible.

\section{References}

1. Celermajer DS, Chow CK, Marijon E, Anstey NM, Woo KS (2012) Cardiovascular disease in the developing world pre-valences, patterns, and the potential of early disease detection. J Am Coll Cardiol 60: 1207-1216.

2. Nettina SM (2015) Lippincott manual of nursing practice. Lippincott William and Wilkins publishers pp: 428-437.

3. Brunner, Suddarth's (2008) Text book of medical surgical nursing. Lippincott William and Wilkins publishers, New Delhi, India pp: 823-824. 